\title{
Martin Greeley
}

\section{Introduction $^{1}$}

There are three main debates which relate to the impact of energy-agriculture interactions on poverty. The first concerns responses to the impact of oil price movements on the price, and hence use of energyintensive agricultural inputs. The underlying concern is the direct impact on the poor due to an increase in the real price of food ${ }^{2}$ in response to oil price increases. Research on or relating to direct energy-food price interaction can be divided into three distinct categories: energy analysis, partial equilibrium models; and research, design and development of renewable energy technologies. The second debate is macroeconomic and concerns the analysis of oilshocks on the expenditure and consumption linkages between agriculture and the rest of the economy. In the broadest sense, the limited literature in this field is a sub-category of and therefore co-extensive with that on adjustment and stabilisation, although there are relatively few studies that focus specifically on either agriculture or poverty and even less that provide an integrated analysis of both.

The third main debate concerns current and potential future utilisation patterns of biomass and the implications for agriculture. There are many strands to this debate but two main themes underlie it. The first is one of woodfuel crisis in which the increasing scarcity of rural domestic cooking fuel in some countries directly and particularly affects the welfare of women within poor rural households - even though the crisis is not usually caused by their fuelwood use patterns but is due to land clearance for agriculture and urban and small industry fuelwood demand. There are repercussions on crop production as both land and labour resources are diverted to fuel provision instead of food; and land productivity is reduced because of soil erosion and because organic residues are used for fuel instead of fertiliser. The second theme, in marked contrast, recognises in the oil crises an opportunity to use agricultural and other

\footnotetext{
This article arises from a joint research project on Energy and Agriculture between the Agrarian Research and Training Institute, Colombo and the Institute of Development Studies. The financial support of the Overseas Development Administration (UK) is gratefully acknowledged.

${ }^{2}$ In this article the principal focus is on food-agriculture, as opposed to non-food crops, and the terms 'food" and 'agriculture' are generally used interchangeably.
}

land to grow fuel crops -- for direct use or after conversion into a higher form of energy such as gas or liquid fuel - which, with high oil prices, will be profitable and raise rural incomes. For the poor, the key issue is obviously the extent to which technologies, resource ownership and production relations will enable them to enjoy improved livelihoods from fuel crop production.

This article focuses on the first debate, the direct agriculturally-related effects of oil price movements on the price and volume of food output. This is for two reasons. First, because it complements the other articles in this Bulletin, most of which - though not limited to agricultural linkages - focus on the biomass debate but include a macroeconomic analysis of energy and poverty interaction in Nigeria by Paul Collier and a paper by Ignacy Sachs et al on the fuel alcohol programme in Brazil, which links the biomass and macroeconomic debates. Secondly, this article arises from recently completed field research on energy and agriculture in Sri Lanka in which a principal emphasis was upon the oil price-food price relationship. Clearly though, these debates are not separable in the sense that they frequently relate to policy in overlapping ways and an holistic view is therefore fundamental to informed policy formulation. The concluding section considers how future analysis of the direct energy-agriculture linkage could contribute to such policy formulation.

\section{The Energy-Agriculture Interface}

1. Developing country agriculture is becoming increasingly dependent upon energy-intensive agricultural inputs, notably oil fuels and inorganic nitrogenous fertiliser.

2. Oil price increases can therefore be expected, more and more, to result in higher agricultural prices in general and, most significantly for the rural poor, higher food prices in particular.

3. The effect of this price rise on food deficit farm households and on households dependent on wage labour is to reduce their food purchasing capacity unless there are compensatory changes in income.

4. And since, in general, ${ }^{3}$ food expenditure occupies

See Lipton (1983) for evidence of discontinuities amongst the poorest households in the inverse relationship of income and proportion of outlay on food. 
an increasingly high percentage of total household outlays as per capita income falls, it is the poorest households which will be most severely affected

In very summary form, these four points describe the logic underlying much of the research agenda on energy and agriculture interactions. It would be pretentious to attempt a truly comprehensive assessment of the policy debate in the space available - development studies has its own growth industries, and this is one which enjoys considerable 'latecomer' advantages. With this significant caveat, the following discussion reviews the debate under four major sub-headings:

a) the basic energy-agriculture relationship;

b) energy analysis;

c) partial equilibrium models;

d) renewable energy technologies (RETS).

The first of these topics concerns the factors which influence the specific character of the energyagriculture interaction with respect to both technical parameters and price relationship. The other three topics represent specific approaches in research; they are quite distinct approaches but all derive their motivation from a common view on the rising fossil fuel intensity of agriculture. These four topics represent the mainstream of research on the direct energy-agriculture interface. However, before turning to them there are two further topics, not covered by this agenda, which need to be mentioned.

First, agricultural research also has a very obvious and significant effect on energy-agriculture interactions. A great deal of plant-breeding work has been explicitly concerned with improving plant growth (or more precisely, growth of edible matter) responsiveness to nitrogen; and, as such, it is responsible for the current dependence on fossil-fuel based nitrogenous fertilisers. This is inevitable when breeding for maximum yields under optimal growing conditions but other research priorities are also now prominent; for example, maximising response at lower fertiliser dosage levels. Moreover, other objectives such as pest-resistance, drought-tolerance, or improved processing qualities can reduce the energy intensity of agriculture. Because of the multiplicity of breeding objectives combined with a multiplicity of possible energy effects (fertiliser use, farm power use, processing energy demand) it is difficult to measure or assess the responsiveness in agricultural research which could be expected to have accompanied the shift in relative factor prices associated with the rise in real oil prices.

However, there have been some explicit responses such as conservation farming programmes, which, amongst other things, commonly seek to reduce fossilfuel energy dependence. So far, conservation practices have seen only very limited use in developing countries; although some practices, such as minimum tillage, are in widespread use in developed countries, their impact on fossil fuel use has been ambivalent because savings in one operation have been replaced by additional energy-intensive expenditure elsewhere (pesticides and fertilisers). In the longer-term there are great expectations about a second development in agricultural research, the application of new plant biotechnologies to reduce dependence on fossil-fuel based nitrogenous fertilisers. However, those technologies based on genetic engineering are far from realisation and the economic viability of other approaches such as use of Rhizobium inoculant, or Azolla are contested [Appropriate Technology International 1985; Rosegrant et al. 1985].

The second topic which has not been listed here as part of the mainst ream debate but which is certainly crucial to oil-price : food-price interactions is the use of fossilfuel energy in the postharvest sector. The developing country postharvest food system, according to Parikh and Syed [1986:36], used 2.7 times more direct fossilfuel energy on average than agricultural production. This figure ignores indirect energy use such as in fertilisers, which is a serious omission in trying to compare the relative sensitivity of the two parts of the food producing sector to oil price movements. Also, the ratio of postharvest to food production energy use is lower (1.7 in the Far East) in poorer countries and where the proportion of marketed surplus is lower. However, it does suggest that from a consumer's, rather than a producer's perspective, neglect of the postharvest sector is a crucial omission in contemporary debate on energy and food interactions.

\section{a) The basic energy-agriculture relationship}

Both cross-sectional and time-series analyses demonstrate unequivocally the strength of the relationship that can exist between use of fossil-fuel energyintensive inputs and land productivity. In so far as output growth is due to yield increases rather than area extension this basic relationship between energy and agriculture is of central significance. There are two types of problem. First of all, the strength of this physical relation ship - known as the energy intensity or energy coefficient of food depending on how it is measured [Greeley 1984] - varies enormously. Secondly, even when the physical relationship is strong, it is typically extremely difficult to successfully measure its economic significance relative to other influences on price formation. These two issues are discussed in turn.

The two main components of the physical relationship are the use of fertilisers and the use of mechanical power (for irrigation pumps as well as tractors and other farm machinery). There are very significant country variations, related to mix of resource endowments and stage of development, but on average in the ldcs around two-thirds of fossil fuel 
energy use attributable to agriculture is that employed in the manufacture and distribution of fertiliser [Stout 1979:97]. In general, the poorer a country is and the higher its man-land ratio, the higher also is the share of fertiliser energy in the limited fossil fuel energy employed in agriculture.

Output growth is becoming increasingly dependent upon fertiliser-intensive yield increase (through use of HYVs) rather than area extension, and the energy costs of marginal output are therefore also increasing. Moreover, because of factors such as risk and access to supplies it is likely that the regional distribution of fertiliser use results in sustained differential application levels; such differentials are, of course, expected to the extent that marginal physical products vary. But, this regional differentiation can and does result in imbalanced regional application such that the marginal physical product in the using region has diminished beneath that in the neglected region - this further increases the commercial energy costs per unit of food output.

However, despite variable but growing dependence on fertilisers and inefficiencies in use there are two factors, other than substitution possibilities, which militate against a simplistic assumption that agricultural growth is inherently more energy intensive because of nitrogenous fertiliser dependence. First, the manufacturing technology is not static and technological improvements since the 1940s have resulted in a fall of 40 per cent in the energy cost (from around 100 megajoules to about 61 megajoules) of the average kilogram of nitrogen [Smil et al 1983:181]. Secondly, product innovation and application innovation have raised, and have considerable potential to further raise, the output elasticity with respect to energy embodied in fertiliser.

In the case of farm power similar arguments concerning manufacturing and use efficiency also apply; in addition there are other reasons for questioning the significance of the farmpower : crop output relationship in the context of oil price rises. The dependence of future output growth on yield enhancement rather than area extension results, on average, in the elasticity of farmpower use with respect to output being below one. In a 90-country study, FAO [Alexandratos et al 1982] estimates that this elasticity will have a value of 0.55 in the period $1980-$ 2000 with an assumed annual growth rate in crop output of 3.5 per cent. This total power requirement is met from human, animal and mechanical sources; the share of tractors and other farm machinery will increase and the marginal product of mechanical power will fall (though the marginal product of total farm power is increasing). However, the rate of substitution (tractors for human/animal power) is much more highly correlated with per capita income than with increase in yield per hectare and Binswanger
(1978) in an authoritative review of South Asian experience, rejects the general validity of the net contributor view of agricultural mechanisation. ${ }^{4}$ This is an important conclusion for the majority of the world's poor who live in countries with high man-land ratios because it suggests that required food output growth will be possible, given the right policies, without substantial use of mechanical power - which will only be used as real wage increases make it profitable to do so and not because it is necessary to feed growing propulations.

Turning from the physical input-output relationship to the price relationship, the best summary price indicator with respect to energy use in agriculture is the price ratio of nitrogenous fertiliser to the dietary staple. The data given below ${ }^{5}$ describe, for Sri Lanka, the number of kilograms of paddy output required to purchase one kilogram of nitrogen in Urea.

\section{Kgs paddy required to purchase $1 \mathrm{~kg}$ nitrogen}

$\begin{array}{cc}1972-73 & 1.61 \\ 1973-74 & 1.25 \\ 1974-75 & 4.36 \\ 1975-76 & 4.83 \\ 1976-77 & 2.92 \\ 1977-78 & 2.39 \\ 1978-79 & 4.33 \\ 1979-80 & 1.99 \\ 1980-81 & - \\ 1981-82 & 4.03 \\ 1982-83 & 4.09 \\ 1983-84 & 3.42\end{array}$

There is no evident upward trend in this data and similar results have been observed elsewhere [India, for example, reported in Leach 1985:29]. This suggests that, from a producer perspective, price has not been a disincentive since at current fertiliser application levels, marginal physical product is typically well above this price ratio [Avadhani et al 1986:17].

The obvious reason for this situation is the existence of price controls, particularly of subsidies on fertiliser inputs. These have been substantial, up to 85 per cent in Sri Lanka for Urea in 1980-81 [Volz and Jayatillake 1982:2] although, in recent years in Sri Lanka, they have been substantially reduced. ${ }^{6}$ The distorting effects of input subsidies have become an almost permanent theme of World Bank, US AID, and other donor agency policy dialogue on agriculture; the Sri

\footnotetext{
4 See Farrington and Abeyratne (1982) for similar analysis of farm power in Sri Lanka.

5 These results are derived from price data on fertilisers and paddy compiled by J. Kottege (ARTI) in an unpublished report.

${ }^{6}$ The monetary value of the subsidy has been held constant for five years so the real value has fallen dramatically.
} 
Lankan pattern of gradual reduction in subsidy levels has been widely repeated, in large part as a response to donor pressures to use open market operations in the crop output market instead to control food prices. These subsidies, resulting in a shift of the increased domestic resource cost of fertiliser use from food buyers to the government, have effectively prevented meaningful empirical analysis of the impact of oil price rises on the volume of food output, food prices and hence, the welfare of the poor. To the extent that this substantial resource cost (fertiliser subsidies were about 1.33 per cent of GDP in Sri Lanka at the peak in 1980 ) is attributable to rising energy costs it serves to emphasise the critical nature of the energy-agriculture interaction. However, there are other major political and economic factors affecting agricultural inputoutput price ratios and as the table above indicates there have been large swings in the relative prices of fertiliser and food.

Moreover, there are two factors on the fertiliser supply side that have been as important as energy costs in influencing price. First, the energy intensity of fertiliser production has fallen. In addition to the process improvements referred to earlier this has been due to the increasing share of natural gas in the energy feedstock which has the advantage of a higher conversion efficiency (energy ratio) than feedstock such as oil or coal. Moreover, for structural reasons, the opportunity cost of gas supplied to new fertiliser plants is often extremely low. Hrabovszky [1986:8] estimates that only 25-30 per cent of fertilisers costs are now attributable to energy costs. Secondly, the fertiliser industry is subject to cyclical price movements related to lumpy plant investments and long gestation periods so oil-fertiliser price ratios in the world market also move erratically. As a result of these factors, the transmission elasticity, that is the proportionate change in the energy-using agricultural input price associated with change in energy price, has varied in the short-term and has a long-term downward trend.

To summarise, there is considerable variation in the physical relationship between use of energy intensive inputs and crop output; there is independent variation of relative prices. The energy-agriculture relationship is therefore very difficult to parametrise. This is of particular significance for the two very distinct approaches to evaluation of energy-agriculture interactions discussed next; energy analysis and partial equilibrium models.

\section{b) Energy analysis}

An unfortunate obscuration in the analysis of energyagriculture interactions has been the emphasis sometimes given to energy analysis. In essence, this emphasis has focused on the energy ratio, that is the caloric energy value of food output divided by (calorie) energy input, as the critical parameter which research and policy decisions ought to seek to maximise. According to the approach, at least in its most extreme form, an energy theory of value underlies economic relations; hence, products with the highest energy ratios will, in the long run, be the cheapest to produce. The less extreme form merely recognises current energy costs as the binding constraint on improved crop productivity and hence also supports the objective of maximising energy ratios in agriculture. The obvious problem is that there is no necessary relationship between this objective and policy objectives expressed in terms of output or consumption. Moreover, because different primary sources of energy have different costs and provide different efficiencies in specific end-uses (e.g. windpower or kerosene pumpsets for lifting water) it is impossible to relate energy ratios to price ratios.

Some researchers [e.g. Reddy and Subramanian, 1980] have developed technological choices centred on first law efficiencies but have ultimately drawn their policy conclusions based on price ratios. However, this approach, which is sensible because it effectively makes the energy analysis redundant, has not been shared by everyone; scarce research resources have been used to advocate or develop technological choices based on maximising energy ratios or, since reliance on imported oil is seen as the problem, maximising farm- or village-level energy selfsufficiency. In effect, a legitimate and rational interest, in response to higher oil prices, of energy conservation in rural development has been translated into a form of energy determinism that is counter-productive and is in fact most detrimental to the welfare of the poorest households who can least afford inefficient use of their scarce resources. Moreover, selecting the volume and mix of output based on energy ratios will inevitably discriminate against energy-intensive inputs when, on economic criteria, they may be fully warranted. Comparison of energy ratios [e.g. Pimentel and Pimentel 1979] shows that maximising energy ratios is achieved by very traditional land-extensive and labour-intensive production methods; yet, as Timmer [1975:214] remarks "Mexican "axe and hoe" agriculture will not solve the "food crisis"; it is part of the problem'. This remark applies with equal force to much of traditional agriculture. We suggest that, to paraphrase Timmer, 'energy analysis' will not solve the food crisis, it is also part of the problem.

\section{c) Partial equilibrium models}

Several studies [e.g. Timmer 1975, Syed 1983 and Modak et al 1986] have outlined a theoretical quantitative framework to link oil price movements to food prices by deriving a (stylised) equilibrium of food supply and demand functions. On supply, the crop production function is specified in terms of energyusing inputs and other inputs. The demand function 
for food is generally specified in terms of food price and other factors (notably income and population growth). Profit-maximising behaviour is assumed and with energy and output prices given, an initial equilibrium of supply and demand can be described. Starting from this equilibrium position, the model specification is designed to isolate, ceteris paribus, the direct response of output to exogenously determined price changes in energy-using inputs. This initial output response in turn triggers an output price response, given by the price elasticity of demand; this in turn provokes a further supply response and the process continues until a new equilibrium is reached. The new equilibrium embodies the changes in the price and volume of output in response to the oil price movement; with small changes in method, the approach can also be used to explore, for example, the effects of input subsidies or the input-output price ratios necessary to achieve a given level of output growth. It has also been suggested as a way to examine the differential impact of oil price movements on farmers using different levels of energy-intensive inputs and with different proportions of marketed surplus in total production [Syed 1983].

Our concern here first of all is to describe the main conclusions from this partial equilibrium approach, and secondly, to assess the robustness of the assumptions implicit in such models in the light of the earlier discussion of the 'basic' relationship between oil prices and food prices.

The first major point to note on conclusions is that, so far, there have been no studies which have actually operationalised this approach using developing country data. Instead, results have been suggested based on the probable size and sign of the two key parameters: on the supply side the key parameter is the elasticity of output with respect to energy inputs which, with neoclassical conditions assumed (perfect competition and profit maximising behaviour), yields expressions for the elasticity of supply with respect to both energy price and output price. On the demand side the key parameter is the price elasticity of demand. Timmer (1975), for example, uses illustrative values of 0.25 and -0.2 for these two supply and demand parameters and derives an elasticity of output price with respect to energy price of 0.625 ; in discussion, he suggests that the value for this elasticity is generally likely to be between 0.3 and 0.8 ; that is, a 10 per cent change in oil prices is likely to lead to an increase in food prices between three and eight per cent. Syed (1983) using an essentially similar framework shows that in response to energy price rises, energy use will fall as will food output, and food prices will rise.

Given that food demand is relatively inelastic and that food output is dependent on energy use, these results are of course not surprising. How valid are the assumptions? The demand side assumption, for an aggregate food production function, of a relatively low elasticity is perfectly reasonable for developing countries; also, the introduction of other long-run demand considerations such as population and income growth will strengthen the conclusions. However, on the supply side two implicit assumptions are questionable; the first of these is the transmission elasticity relating the price of energy-intensive intputs to oil price movements. In developing country agriculture the most important energy-using input is fertiliser and, as discussed above, there are both structural and technical reasons why this transmission elasticity relating the price of energy-intensive inputs output with respect to energy-intensive input use ignores substitution possibilities and the possibilities for increased efficiency due to better inter-regional, inter-farm and inter-crop utilisation of energyintensive inputs. As both Timmer and Syed recognise, substitution through use of less energy intensive techniques of production or less energy-intensive crops would considerably weaken the depressing conclusions of these models. There are also considerable possibilities, as mentioned earlier, to improve the response of output to energy inputs by, for example, better application methods for fertiliser or improved machinery design. Thus, the conclusions to be drawn from these partial equilibrium approaches have to be treated very cautiously; their message is critically dependent upon assumptions about supply response which are static in their treatment of technology and require determination of an essentially artificial parameter - the fixed output elasticity with respect to energy use.

\section{d) Renewable energy technologies}

Of the major areas of debate on energy-agriculture interactions the literature on renewable energy technologies is by far the most substantial. Renewable energy technologies (RETS) in agriculture are concerned mainly with substitution of fossil-fuel using farm power (especially water-pumping and other stationary power needs) by wind, solar and biomass using energy technologies - improvement of draught power is a further category which by some definitions is not strictly speaking a RET but can be conveniently included here. Their potential impact on poverty is two-fold; first, and most obviously, by allowing essential food production tasks to be completed with less cost thereby reducing the relative price of food. Secondly, through being more labour-intensive and having stronger growth linkages with the local economy than fossil-fuel using inputs they increase the share of labour in value added and provide demand for - and therefore jobs in - other sectors. The strength with which this latter characteristic is found in RETS obviously varies; imported solar photovoltaic irrigation pumps for example have little need for local labour. But most RETS are more labour 
intensive in either manufacture or use (or both) than their fossil-fuel competitors.

To date, these two potential impacts have not yet been realised on any significant scale and there has been extensive analysis of why RETS programmes have failed to fulfil expectations; the issues involved overlap quite considerably with analysis of appropriate technology and it is not proposed to try and address these here. There are however three basic issues which are of special importance.

First, despite the mushrooming of funding on RETS in recent years the total expenditure - of largely public capital - in research, design and development is very, very much lower than that - largely private capital -directed towards fossil fuel powered machinery. RETS are heavily under-researched. This is reflected in results; for example, in Sri Lanka as elsewhere there have been substantial recent improvements in (Japanese-designed) engine-water pump system efficiencies for fossil-fuel powered engines whereas competing RETS such as gasifiers, solar pumps and windmills have had varying but on average very limited resources to pursue design optimisation.

Secondly, and in part as a consequence of underresearch, the economic viability of many RETS has not been established. In many situations specific RETS are only likely to be viable after further significant increase in the real price of oil. Also, a specific disadvantaging feature of many RETS is that, compared to their fossil-fuel powered competitors like diesel engines, they have relatively high fixed investment costs - their costs savings are of variable costs in the form of fuel. For poor farm households, with limited access to cash or credit and with very high subjective discount rates, this worsening in the distribution of costs may be a significant drawback.

Thirdly, the macroeconomic environment is biased against these types of technological change [Stewart 1986]. The organisation of individual and institutional incentives favours 'high' technology research and development. Pricing and fiscal policies and, more fundamentally, asset distribution, frequently discriminate against labour-intensive technologies, and therefore often adversely affect RETS. None of these difficulties is easily overcome, so even though the probability of the long term viability of most RETS is equal to the (high) probability of much higher longterm real oil prices, they are unlikely to substantially benefit either agriculture or the poor in the short or medium term.

\section{Conclusions: Energy-Agriculture Interactions and Research Priorities}

This short review of the four main research topics on energy-agriculture interactions has necessarily been selective; the general emphasis has been on identifying weaknesses in current approaches. In the case of energy analysis and partial equilibrium models the main criticisms were methodological: i.e. the way in which research issues are formulated and the capacity of the method to provide relevant analysis. In the case of RETS, where research, design and development strategies obviously show significant variation and where there is considerable initiative to improve research methods [Barnett 1986], the weaknesses alluded to concerned barriers that even good RETs research programmes could not easily overcome.

However, the more fundamental problem identified, which relates to all three research topics, concerned the facts regarding the impact of oil prices on energyintensive agricultural input prices. There were several influences identified, on both the physical inputoutput relationship and price-formation, that called into question the more alarmist views on the energyfood price relationship. The experience of other sectors is of interest here. One of the early controversies, during the $1970 \mathrm{~s}$ boom in energy studies, was the relationship between energy intensity and capital intensity. Early econometric studies identified a close relationship between energy intensity and capital intensity in industry. However, these were necessarily based on periods when energy was cheap and there is now substantial evidence that capital and energy can as often be substitutable as complementary resources [Mork 1981]. Given the laws of biology and physics there is a clear limit to energy substitution in food production; but, that limit is far from being a binding constraint and technological change can be expected to continue to reduce the energy intensity of food.

Because such changes are constantly occurring, up to date situation-specific analysis of particular energycrop output ratios is necessary to provide a firm foundation for either energy analysis or partial equilibrium models. Such analysis is uncommon and expensive, and useful results from these approaches is therefore threatened. In the case of energy analysis this is no great loss since the emphasis in this approach upon energy out put-input rather than rupee or dollar output-input relationships limits its relevance to very specific contexts, e.g. the impact of an energy tax. It is of little use in understanding how food prices might be affected by energy prices. In the case of partial equilibrium analysis, a potentially valuable tool is weakened, and as Mork [1981:39] commented 'the ability to model energy price changes will improve but at this stage good judgement is as important as good econometrics'.

The difficulties of providing useful policy advice through these research approaches are clear. We suggest that they ultimately reflect too static a preoccupation with responding to a 'crisis' whereas in the real world, policy measures, technical change and broader economic considerations have transformed 
the nature of the problem. In reality the most important area for analysis of fertiliser dependence, for example, has often been its effect on the balance of payments. Many countries have restricted farmers' access to energy-intensive inputs, which is likely to increase food prices, because of foreign exchange shortage. Moreover, in recent years it has been exchange rate movements (especially of dollardenominated ldc exchange rates) not energy price movements that have caused the balance of payments burden of agricultural inputs to remain at a very high level. For these issues macroeconomic research that explores the effect of stabilisation policies on poverty [e.g. Addison and Demery 1983] is needed. The direct energy-agriculture interaction is a less useful focus. ${ }^{7}$

In the case of RETS for agricultural applications our conclusions are only slightly less gloomy. Whilst a long-term role for such applications seems assured the immediate prospect is usually very limited, because of underresearch, high cost and poor macroeconomic environment. The emphasis on RETS for agricultural applications has perhaps also been too strongly driven by a sense of 'crisis' due to fossil fuel dependence. As careful modelling work has shown [Parikh and Krömer 1985] the poor are in fact most likely to be vulnerable to biomass scarcities affecting availability of food, feed, fuel and (organic) fertilisers rather than to energy-intensive agriculture pushing food prices up. However, for biomass programmes the real opportunity for effective poverty-focused intervention does not consist solely of 'fuel for the poor' programmes. A much more significant intervention strategy is planned expansion in production and use of biomass fuel via development designed specifically to generate employment and incomes for the poor. The Brazilian alcohol programme [see Sachs et al. in this Bulletin) is one of the best known biomass-based fuel programmes, but there is no necessary reason for the adverse impacts on the poor there to be repeated. Elsewhere, experience of such programmes (e.g. social forestry) has varied considerably, but with many failures. Programme design is responsive though, and in some countries, e.g. India, there is considerable experimentation with innovative approaches.

There are many interactions with food agriculture, as briefly noted in the Introduction; of more importance though are the rural growth linkages associated with large scale use of bio-fuels. Despite the current food shortages in some countries the significant long-term agricultural growth problem - already faced in India - is not one of food supply but of effective demand

\footnotetext{
There are developed country macroeconomic models e.g. Parsons et al. 1978] which provide a detailed sectoral model in a general equilibrium framework but the data requirements are formidable (detailed input-output tables for the agriculture sector) and the problems with the instability of the energy intensity of production remain. No such approaches have been observed for developing countries.
}

for it. Wherever population densities are high the capacity of agriculture to absorb labour will remain a main determinant of employment, therefore effective demand and therefore agricultural growth; but this employment will only occur through crop diversification. LDCs generally, because of their location, have a high land productivity potential and therefore comparative advantage in producing fuels from biomass. Techniques to produce bio-fuels commercially are also improving rapidly and the oil price at which bio-fuels compete with fossil fuels is therefore falling. These considerations clearly suggest that it is RET interventions on biomass (notably, forestry programmes and fuel crops programmes) that are most likely to provide the clearest opportunities for a positive and controlled strategy to improve rural livelihoods.

\section{References}

Addison, T. and L. Demery, 1985, 'Macro-Economic Stabilisation, Income Distribution and Poverty: A Preliminary Survey', Working Paper No 15, ODI, London

Alexandratos, N., J. Bruinsma, and J. P. Hrabovszky, 1982, 'Power inputs from labour, draught animals and machines in the agriculture of developing countries', FAO, Rome

Appropriate Technology International, 1985, 'Biotechnology and Community Development for Food Production: A Case Study', Washington DC

Avadhani, M. H., V. Kumar, and G. Krishna, 1986, 'Energy Optimisation in the Application of Fertilisers', Paper presented at Second International Workshop on Food Energy Nexus and Ecosystems, February 12-14, New Delhi

Binswanger, H. P., 1978, 'The Economics of Tractors in South Asia', International Crops Research Institute for the Semi-Arid Tropics, Agricultural Development Council, New York

Barnett, J. A., 1986, 'Case Studies in the Diffusion of Energy Technology in Developing Countries - A Synthesis' (Draft -2) Science Policy Research Unit, University of Sussex, October

Farrington, J., and F. Abeyratne, 1982, 'Farm Power and Water use in the Dry Zone', Research Study No 52, Part ii, Agrarian Research and Training Institute, Sri Lanka

Greeley, M., 1984, 'Energy Use and Agricultural Growth: Some Issues in Research', paper presented at the International Seminar on Ecosystems, Food and Energy, Brasilia, September

Hrabovszky, J. P., 1986, 'The Inputs and Outputs of Rural Energy', UN Work in Progress, Vol 10, No 1, October

Leach, G., 1985, 'Energy and Agriculture', International Institute for Environment and Development, London 
Lipton, M., 1983, 'Poverty, Undernutrition, and Hunger', World Bank Siaff Working Paper, no 597, Washington DC

Modak, S., T. Moulik, and P. Shukla, 1986, 'An Economic Model of Relation Between Food and Energy Sectors' in Second International Symposium on Food-Energy Nexus and Ecosystems, Indian Institute of Management, Ahmedabad presented at International Workshop on Food and Energy Nexus and Ecosystems, February 12-14

Mork, K. A., 1981, 'Energy Prices, Inflation and Economic Activity' MIT Center for Energy Policy Research, Ballinger Publishing Co, Cambridge (Mass)

Parikh, J. K. and G. Krömer, 1985, Modelling Energy and Agriculuure Interaciions: An Application to Bangladesh, International Institute for Applied Systems Analysis, Laxenburg, Austria

Parikh, J. and S. Syed, 1986, Energy Use in the Post-Harvest Food (PHF) Sysiem of Developing Countries, International Institute for Applied Systems Analysis, Laxenburg, Austria

Parsons, S. T., A. J. Rayner, G. V. Reed and R. J. Young, 1978, 'Oil price inflation and British agriculture' Oxford Agrarian Siudies 7, pp 105-24

Pimentel, D. and M. Pimentel, 1979, Food. Energy and Sociely, Edward Arnold, London
Reddy, A. K. N. and D. K. Subramanian, 1980, 'The Design of Rural Energy Centres', in A. K. N. Reddy (ed), Rural Technology, Indian Academy of Sciences, Bangalore, pp 109-30

Rosegrant, M. W., J. A. Roumasset, and A. M. Balisacan, 1985, 'Biological Technology and Agricultural Policy: An Assessment of Azolla in Philippine Rice Production, American Journal of Agriculiural Economics, Vol 67, No 4, November

Smil, V., P. Nachman, and T. V. Long, 1983, 'Technological Changes and the Energy Cost of US Grain Corn', Energy in Agriculiure. No 2, pp 177-92 (Elsevier Science Publishers)

Stewart, F., 1987, 'Overview and Conclusions', in F. Stewart (ed.), Macro-Policies for Appropriale Technology. Westview Press, Boulder Co (forthcoming)

Stout, B. A., 1979, Energy and Agriculure, FAO, Rome

Syed, S., 1983, 'Higher Energy Price and Agricultural Production in the Developing Countries - An Analysis of the Role of Pricing Policies', FAO, Rome, (mimeo)

Timmer, P., 1975, 'Interaction of Energy and Food Prices in Less Developed Countries', American Journal of Agricultural Economics, Vol 57, No 2, May

Volz, U., and K. A. K. Jayatillake, 1982, Review of the Ferilizer Year 1981, National Fertilizer Secretariat, Ministry of Plan Implementation, Colombo 